\title{
Study on the Function of XBRL and the Enhancement of the Accounting Information Quality under the Background of Informationization
}

\author{
Xin Yuan \& Yanyan Wang \\ Shandong Economic University \\ Jinan 250014, China \\ E-mail: yuan_xin1984@163.com
}

\begin{abstract}
As a new information standard and technology supporting the accounting internationalization and the globalization of financial report, XBRL (eXtensible Business Reporting Language) has not been concerned by Chinese enterprises and accounting personnel in the time that the informationization develops so quickly. Under the background of informationization, the functions of XBRL are discussed in the article to enhance the accounting information quality, which indicates that China should well grasp the demands of the economic development and the promotion function of the accounting information processing technology to the accounting.
\end{abstract}

Keywords: Informationization, XBRL, Accounting information quality

\section{Definition of XBRL}

According to the definition of XBRL international organization, XBRL is a kind of language used in the electric communication of enterprise financial data, and it is thought to be changing the financial reporting mode of the world now. XBRL was developed to compile and issue network financial reports for the corporation, basing on the XML (eXtensible Markup Language) framework. It adds the marks to relative financial information to make the collection, processing and conversion of interior and exterior financial information become more convenient and effective. The biggest difficulty in the R\&D of XBRL is to establish the XBRL classification system according with the rules of the financial report to make XBRL suit for the current financial reports.

\section{Characters of XBRL}

XBRL is the technical standard which is opening and free, and can be widely acquired. It can offer only identifiable mark for each meta-code, and these marks can be read by the computer. For example, after the only mark of the retained profits is set up, the computer can automatically process the information of the report forms of the company, which can largely reduce many manual works such as repetitively inputting, comparing and analyzing. The computer can "intelligentize" the data of XBRL, and identify, pick up, analyze and store the information of the XBRL documents, and exchange information with other computers, and automatically report according to users' required forms. XBRL can quicken the processing speed of financial data, reduce the mistakes, and automatically check information. The present report form of the enterprise reporting to the supervision department is the information format based on text or natural text expressed by commercial language. But the reports with XBRL form adopt the information based on document expressed by the computer language, which can translate the present text information into the information which can be automatically picked, searched and analyzed, and realize automatic exchange of data on different software platforms including internet, and reduce or avoided inconveniences and mistakes.

In recent years, XBRL has been widely applied all over the worlds, and many national securities supervision institutions and exchanges such as SEC, CSA, Toronto Stock Exchange, Korea Exchange, Tokyo Exchange, Shanghai Exchange and Shenzhen Exchange all have participated in the application of XBRL. The application of XBRL has gradually been embodied in various parts of the financial report chain.

\section{Influences and functions of XBRL in the enhancement of the accounting information quality}

The influences and functions of XBRL in the enhancement of the accounting information quality are mainly embodied in following aspects. 


\subsection{Enhancing the relativity, reliability and in-time feature of the accounting information}

On the layer of system, the accounting rules standardize the accounting information quality standards, but it still adopts the traditional financial report mode which could offer highly comprehensive and general financial information to information users, but ignore the differences of different information users' demands, lack in non-coin information descriptions for the enterprise management activities, inevitably lose the meanings of many accounting data in the processes such as classifying, manufacturing and collecting and increase the difficulty to distinguish information for users. The traditional financial report mode adopts the reporting mode on the appointed time and position, which is difficult to fulfill information users' requirements for the time-sensitivity of the information in the information economic time.

XBRL offers a new financial report mode in the internet environment, which takes the XML as the technical base. Because XML is a kind of "meta tag language", it can divide the contents and the report format, and allow users to define corresponding data marks (tags) according to their own demands. The technical frame of XBRL includes XBRL Specification, XBRL Laxonomy, XBRL Instance and XBRL Stylesheets. The classification standard of XBRL financial report is the total appellation of various tags on each information element attached the financial report, and it is used to define the data elements in the instance documents and the relations among these elements, and its main intention is to offer a standard which can present the financial information of different industries and enterprise by same form. The instance document is the set of data elements which corresponds with the original codes in the financial report of the enterprise. The Stylesheet of XBRL is mainly used to define the display format of the financial report, and for the XBRL instance documents in same financial report, it can output various report forms by different stylesheets.

The application of the XBRL technical principle on the layer of the financial report is to classify a kind of non-structured information texts (such as the Word format or the PDF format) of the financial report according to standard financial information meaning, and make it to become standard "information material" of financial report with tags, i.e. translate the electric non-structured financial report texts of the enterprise into the structured XBRL instance documents with tags, convenient for further processing of information technologies such as structured text searching technology and the information analysis in the internet environment. Therefore, by adopting the financial report of XBRL format, information users need not seeking required "information materials" from deep financial report texts, and because these "information materials" all possess standard format with uniform tags, which can fully utilize the computer software technology to compare, and largely enhance the decision pertinence of the accounting information by exporting useful accounting information by different stylesheets.

The XBRL disclosing technology requires the enterprise to explain the standards such as the accounting rules and policies followed by the financial report (such as adopting the historical cost or the fair value), and store the promissory explanation documents with clear concepts on the information platform of the enterprise, and make them in the state of checking, which can increase the intelligibility of "information materials", and help information users to comprehensively understand the financial report, and enhance the reliability of the accounting information.

In addition, the financial report of XBRL format can be disclosed in the website of the company, and can be issued on the appointed website, which can fully exert the advantages of the internet and the computer information processing technology and the enhance the in-time feature of the accounting information.

\subsection{Developing and utilizing the financial information resources to enhance the applied values of the accounting information}

The development and utilization of the financial information resources means the process separating, collecting and reprocessing financial information in the financial report and generating new and more valuable economic information. The quick development of the computer network and information technology offers the support for the development and utilization of financial information resources. And the present financial reports issued by PDF or WORD or HTML format are just the electric paper financial reports which can be read only the read software. If the financial report data of relative enterprises or certain enterprise in past years need to be collects, the costs and risks of data acquirement will be increased largely, which can not fulfill the development of the potential application of the network technology.

XBRL will change the compiling mode and the reporting mode of financial information radically, and it could offer a new technical system about standards and specifications for enterprises to compile, store and issue financial reports and other information on internet, and it can the essential problem about the integration of financial information disclosing and financial data acquirement and the trans-platform use, and the information users all over the world can quickly search, collect and analyze the enterprise financial information according to their own demands by internet. For example, Shanghai Exchange and Shenzhen Exchange could convert the electric general financial reports referred by enterprises into structured instance documents with uniform tags and XBRL format by the XBRL format converter for storage. The information users can directly enter into the application software to analyze and process the data of financial reports on the website, and generate various reports by relative tool software, which can help users to make 
optimal decisions, and further enhance the application values of the accounting information.

3.3 Improving the interior management information system platform of the enterprise and utilizing the accounting information in time to enhance the management performance

XBRL can strengthen the communication among information systems in the enterprise and the repetitive utilization of trans-platform data, help to compile the interior management accounting reports and enhance the comprehensive utilization level of the management accounting information. For the large-scale enterprises especially for the group enterprises, the networking management information system is the platform for the enterprise to implement the management and operation. But the information systems of these large-scale enterprises or group enterprises are established and perfected gradually. Generally, the application platforms of the information systems among different sub-companies or departments, and especially for the group enterprises which engages in the productions and managements of different industries, the interior different databases or different management information systems will induce the obstacles of data exchange and data sharing among interior information systems in the enterprise, which can not fulfill the senior managers' information demands. The technical principle of XBRL platform independent can offer solutions with low cost and high quality for the data exchange among different information systems. It can design the I/O conversion interface with uniform format and function based on XBRL for original information system, which can combine and collect information generated in different information systems in the enterprise and fulfill the comprehensive application demands of the enterprise group for the interior management information, and enhance the quality of the interior control. The application of XBRL bottom classification standard can help the management layer of the enterprise to inquire relative detailed information at any moment when reading the management accounting report, but not only collect the numbers, which obviously could enhance the managers' comprehensions to the data of the report form, and help them to make effective management decisions.

\subsection{Financial report of XBRL can enhance the transparence of the accounting information}

XBRL allows the financial information to keep the original context, which can enhance the transparence of the accounting information. For example, for one foreign exchange contract, many details such as unit, sum and time can be associated with each factor of the contract. XBRL could add the bar code for each factor in the contract materially, so the users can easily understand and dig the items of the transaction, which can largely enhance the adjustment between the report numbers and the actual cash fluxes.

In addition, large issuance quantity of the financial report can also enhance the transparence of the accounting information. It is very important to offer timely and reliable management performance materials, and XBRL can use public financial materials with any formats to generate financial reports by the application program. The issuance on internet could not only help the investors to make decisions, but help the auditing institution to supervise the financial reports real time.

\section{References}

Pan, Yan. (2003). XBRL and Its Influences on the Accounting. Accounting Research, No.1.

Shen, Yingling. (2002). Research of Network Financial Report. Thesis for Doctor's Degree of Shanghai University of Finance and Economics.

Shen, Yingling. (2004). The Technical View on Accounting Globalization. Accounting Research, No. 4.

Yao, Zhenghai. (2005). XBRL and Its Applications in China. Communication of Finance and Accounting, No.4.

Zhang, Tianxi. (2006). On Internet Financial Reporting: the Theoretical Basis of XBRL. Accounting Research, No. 9. 